\title{
Methaqualone Hydrochloride
}

National Cancer Institute

\section{Source}

National Cancer Institute. Methaqualone Hydrochloride. NCI Thesaurus. Code C2484.

The hydrochloride salt form of Methaqualone. As a sedative, hypnotic agent,

methaqualone was used for insomnia. Due to its high risk for abuse, methaqualone was taken off the U.S. market in 1983. (NCI) 